November 23, 2015

ESMT Working Paper 15-04

\title{
Fund flows inducing mispricing of risk in competitive financial markets
}

Axel Stahmer, ESMT European School of Management and Technology

Copyright 2015 by ESMT European School of Management and Technology, Berlin, Germany, www.esmt.org.

All rights reserved. No part of this publication may be reproduced, stored in a retrieval system, used in a spreadsheet, or transmitted in any form or by any means - electronic, mechanical, photocopying, recording, or otherwise - without the permission of ESMT.

Find more ESMT working papers at ESMT faculty publications, SSRN, $\underline{\text { RePEC}}$, and EconStor. 


\title{
- Working Paper - Fund Flows Inducing Mispricing of Risk in Competitive Financial Markets
}

\author{
AXEL STAHMER *
}

\begin{abstract}
This paper studies the effect of new fund flows on investment behavior and the resulting equilibrium price of risk. The Small Fund Industry model shows equilibria with overinvestment in unprofitable and underinvestment in profitable investment opportunities. The Large Fund Industry model derives market prices for risk and analyzes the resulting price distortions in equilibrium. New flow of funds to the asset management industry lead to inefficient investment decisions, mispricing of risk, and distortion of market implied probabilities. Furthermore, the paper provides an explanation for partial market failure and trade among identical asset managers without assuming heterogeneous beliefs.
\end{abstract}

JEL classification: D53, D80, G01, G02, G11, G12, G20

\footnotetext{
${ }^{*}$ European School of Management and Technology (ESMT) Berlin, Germany, e-mail: axel.stahmer@esmt.org. Special thanks are due to Joerg Rocholl and Paul Heidhues for their extraordinary support and many useful comments that helped improve this paper. I am grateful to the ESMT and Humboldt University seminar participants, in particular Guillermo Baquero and Sascha Steffen as well as Christoph Wagner, Dora Simroth and Benedikt Meyer-Bretschneider for their constructive input. All errors are my own. I also wish to thank the JP Morgan team, which helped develop the paper idea.
} 


\section{Introduction}

In recent years, the responsibility for a significant amount of individual asset allocation decisions has been shifted from end-investors to the global fund management industry. By the end of 2014, mutual funds had attracted net new cash inflows of $\$ 102$ billion and managed $\$ 31$ trillion of assets. ${ }^{1}$ The rationale behind investments in mutual funds is still subject to debate, ${ }^{2}$ the effect on the wider market equilibrium asset allocation decisions and the equilibrium pricing of risky assets has not yet been analyzed. This is the important open question which this paper seeks to fill. External fund flow can cause asset managers to overinvest in bad projects and underinvest in good projects. This behavior leads to distortions in asset allocation, market prices for risk, and market-implied probabilities. As an additional result, this paper provides a reason for trading among fund managers without assuming heterogeneous beliefs. With a growing asset management market, these insights will have increasing relevance for financial market participants affected by the resulting market prices and capital allocations.

The empirical literature has established a robust convex relationship between the performance of asset managers and the flow of funds from outside investors. Previous theoretical approaches seek to explain the flow of funds pattern assuming either rational (Berk and Green, 2004) or irrational outside investors (Rabin and Vayanos, 2010). While the previous literature is focused on analyzing and explaining the convex fund flow pattern, this paper takes the convex relationship between performance and fund flows as given and addresses the implications for prices and investment allocations in competitive financial markets. Intuitively, asset managers incorporate the flow of funds effect in their investment strategy, which leads to decisions that disregard the risk of large but unlikely negative returns, resulting in market inefficiencies that persist in competitive financial markets. First, this paper considers a Small Fund Industry model, in which asset managers' investment

\footnotetext{
${ }^{1}$ Investment Company Institute (2015)

${ }^{2}$ And overview of the discussion is provided by Guercio and Reuter (2014); Gennaioli, Shleifer, and Vishny (2015).
} 
decisions have no effect on prices. The convex flow of funds relation leads to capital misallocation in two ways: Over-investment in negative net present value projects, which are likely to attract new flow of funds from outside investors, and underinvestment in positive net present value projects, if these are unlikely to attract new outside capital. Second, a Large Fund Industry model is introduced, in which market prices are determined within the asset management industry. The model provides an explanation for trading activity among identical market participants and proves the resulting mispricing in equilibrium. A significant increase in new flow of funds leads to market failure for a wide range of investment opportunities and to a distortion of implied probabilities.

This paper relates to three different strands of the literature. First, it relates to the benchmark literature, which widely accepts the concept that fund managers are generally evaluated against an exogenous benchmark (Admati and Pfleiderer, 1997; Basak, Shapiro, and Teplá, 2006). In the literature benchmarking is seen as a valuable tool to judge the performance of investment managers (Rennie and Cowhey, 1990; Binsbergen, Brandt, and Koijen, 2008) while in practice relative evaluation against a benchmark has become so common that following the benchmark is considered a riskless strategy (Brennan and Li, 2008). Basak, Pavlova, and Shapiro (2007) solve the asset managers' maximization problem when fund flows are explicitly linked to the benchmarked fund performance and find risk-shifting behavior on an individual level. This paper, however, analyzes the consequences of investor behavior and solves for market prices in equilibrium.

Second, the paper is related to the subjects of relative wealth concerns (Frank, 1985) and tournaments (Brown, Harlow, and Starks, 1996) in the mutual fund industry. Brown et al. (1996) present evidence that poorly performing funds increase the risk to close the gap with the better performing competition. Generally, the theoretical and empirical findings suggest that tournament behavior in the mutual fund market is induced by end-investors money chasing well-performing mutual funds (Khorana, 1996; Chiang, 1999; Goriaev, Palomino, and Prat, 2003). Negative performance relative to peers can lead to an increase in risk-taking ( $\mathrm{Li}$ and Tiwari, 2006; Kempf and 
Ruenzi, 2008), while positive out-performance leads to a decrease in risky investments (Reed and Wu, 2005). Gyongyi and Emanuela (2006) claim that rank-based incentives have a negative effect on the investor's return on investment and DeMarzo, Kaniel, and Kremer (2007) show that the concern of being left behind leads to stronger herding.

Third, this paper relates to the literature of delegated investment decisions. Sharpe (1981) provides a theoretical framework to analyze the potential distortions caused by delegating investment decisions. Also, Cornell and Roll (2005) highlight the importance of the subject and conclude that models missing the delegation framework can lead to wrong predictions of asset prices. The delegation decision can lead to equilibria with short-sighted investments (Nagarajan, Sivaramakrishnan, and Sridhar, 1995), to herding behavior (Chevalier and Ellison, 1999), lower equity risk premia (Kapur and Timmermann, 2005) and higher trade volumes (Dasgupta and Prat, 2006). Thakor (1990) suggests that asset managers prefer investment opportunities that generate cash returns sooner caused by information asymmetries and moral hazard. Brennan and Li (2008) find that the delegation decision of asset management leads to increased prices and lower returns of assets correlated with important benchmarks. Cuoco and Kaniel (2011) derive a general equilibrium in which fund managers bias their portfolio toward benchmark stocks. Basak and Pavlova (2013) explain that the buying behavior of asset managers generates asset-class effects. Mostly, the literature describes the delegation of portfolio decisions in a principal agent framework. In contrast, this paper models end-investors as non-strategic agents who allocate their capital among the best performing funds, and analyzes the effects on asset allocation and market prices in equilibrium.

The paper is structured as follows. The following section introduces the Small Fund Industry model. The third section introduces the Large Fund Industry partial equilibrium model, in which market prices are determined endogenously. Finally, section four summarizes the results and concludes. 


\section{Small Fund Industry Model}

The Small Fund Industry model assumes a market with an exogenously arising price and payout probability for one investment opportunity. That setup is applicable for markets where portfolio decisions delegated to asset managers only account for a small fraction of the overall market and demand has no influence on prices.

End-investors observe the performance of all asset managers and decide to allocate their capital among the best performers. Asset managers in return maximize assets under management and anticipate the end-investors' capital allocation decision. There are two sources to increase expected assets under management. One source is the investment in positive NPV projects, and the other is the ability to attract new investor money from end-investors. The investment decision influences the fund managers' realized returns and consequently affects the amount of capital he can attract from end-investors.

Two assumptions are essential for the model results: Fund managers maximize their assets under management and end-investors allocate their capital to the funds which show the best performance. Both assumptions are established by the related literature and are taken as given in this paper. First, fund managers are compensated with a management fee based on their net assets according to Khorana (1996), Jans and Otten (2008), and Cuoco and Kaniel (2011). Consequently, fund managers' fees are maximized when assets under management are maximized. Second, end-investors' performance chasing behavior is supported by the literature insight into the relationship between fund performance and fund flows. Most notably Ippolito (1992), Patel, Zeckhauser, and Hendricks (1994), Sirri and Tufano (1998), and Agarwal, Daniel, and Naik (2004) show the positive and convex relationship between fund performance and subsequent fund flows. Recently, Basak and Makarov (2014) stated that "given the prevalent finding in money management that the money flows-to-relative performance relationship is increasing, a fund manager has incentives to outperform her peers so as to increase her assets under management and in turn her compensation." 3

\footnotetext{
${ }^{3}$ Spitz (1970) and Smith (1978) describe the positive performance and flow of funds
} 
The choice procedure of end-investors in this paper is partly based on the framework presented by Osborne and Rubinstein (1998), later also used by Spiegler (2006) to model non-strategic agents who base their reasoning on the observed past realizations of a probabilistic process. The phenomenon of over-inference from past performance or from small samples is well-documented, most notably by Tversky and Kahneman (1971), Kahneman and Tversky (1972) and, Rabin (2002). ${ }^{4}$

\section{A. Model Setup}

The Small Fund Industry model assumes a discrete number of $J$ identical asset managers ${ }^{5}$ indexed by $j$, who individually maximize their assets under management $A_{j}$. Moreover, there are end-investors ${ }^{6}$ with combined wealth $W$, who allocate their wealth among fund managers. Furthermore, there exists the following investment opportunity ${ }^{7} I_{\alpha}$ with $\alpha \in(0,1)$ and $p \in \mathbb{R}$ :

$$
I_{\alpha}=-p+\epsilon_{\alpha}, \text { with } \epsilon_{\alpha}= \begin{cases}1, & \text { with probability } \alpha \\ 0, & \text { with probability }(1-\alpha)\end{cases}
$$

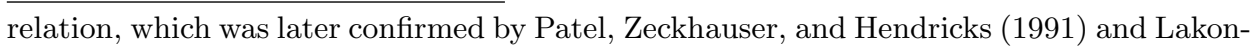
ishok, Shleifer, Vishny, Hart, and Perry (1992). Gruber (1996) shows that investing in well-performing funds can be rational investment behavior, and sees his empirical findings confirmed by Zheng (1999). Lynch and Musto (2003) and Berk and Green (2004) provide models in which the convex relation between past performance and fund flow arises endogenously. Baquero and Verbeek (2005) as well as Ding, Getmansky, Liang, and Wermers (2009) confirm the convex performance flow relation for hedge funds.

${ }^{4}$ Tversky and Kahneman (1971) label the cognitive phenomenon of drawing conclusions from the parent population from a small sample as sample size neglect and demonstrate the effect experimentally (Kahneman and Tversky, 1972). Rabin (2002) incorporates the inference from small sample realizations in a formal model. Lynch and Musto (2003) model investors who condition their investment allocation decision on observable performance. Berk and Green (2004) provide a partial equilibrium model in which investors learn the ability level of fund managers from observing past performances. Baquero and Verbeek (2006) find empirical evidence, indicating that investors base their hiring and firing decision of fund managers on past performance and the mistaken belief in the law of small numbers.

${ }^{5}$ The expressions asset manager, fund manager and manager are used synonymously.

${ }^{6}$ The expressions end-investors, outside-investors and investors are used synonymously.

${ }^{7}$ The expressions investment opportunity, investment and option are used synonymously. 
Asset managers are risk-neutral agents with initial assets $a$ under management. Facing the investment option $I_{\alpha}$ for one fixed pair of $p$ and $\alpha$, they can choose to invest (Option), which involves paying premium $p$ and receiving the realization of $\epsilon_{\alpha}$. Alternatively, they can choose to refrain from investing and follow the riskless benchmark (Bench). Hence, each asset manager is choosing action $x_{j} \in X$ with $X=\{$ Option,Bench $\}$. The action profile $x=\left\{x_{1}, \ldots, x_{J}\right\}$ for all asset managers is sometimes stated as $x=\left\{x_{j}, x_{-j}\right\}$ with $x_{-j}$ being the action profile chosen by all asset managers other than $j$. The behavior of end-investors is taken as given based on the empirical evidence suggesting a convex relationship between performance and flow of funds. Accordingly, end-investors observe the realization of $\epsilon_{\alpha}$ and the investment choice $x_{j}$ of each fund manager before allocating $W$ equally among those funds showing the highest realized investment returns.

The timing is as follows: First, an investment opportunity $I_{\alpha}$ arises with a fixed pair of $\alpha$ and $p$. Second, all asset managers choose $x_{j}$ individually and simultaneously. Third, the investment payoff $\epsilon_{\alpha}$ is realized and observed by the end-investors. Fourth, the end-investors split $W$ equally between the fund managers with the highest investment return. Finally, fund managers observe their final assets under management $A_{j}$. In a reduced form, the new flow of funds received by each individual asset manager are a function of all managers' investment choices and the realization of $\epsilon_{\alpha}$, which leads to $A_{j}=A_{j}\left(x_{j}, x_{-j}, \epsilon_{\alpha}\right)$. With $\mathbb{E}\left[\epsilon_{\alpha}\right]=\alpha$ and an exogenously provided $\alpha$, the expected final assets under management for each fund manager are $\mathbb{E}\left[A_{j}\left(x_{j}, x_{-j}\right)\right]$.

DEFINITION 1 (Nash Equilibrium): A strategy profile $s^{*}=\left(x_{1}^{*}, \ldots, x_{J}^{*}\right)$ constitutes a (pure-strategy) Nash Equilibrium if $\mathbb{E}\left[A_{j}\left(x_{j}^{*}, x_{-j}^{*}\right)\right] \geq \mathbb{E}\left[A_{j}\left(x_{j}, x_{-j}^{*}\right)\right]$ for all $x_{j} \in X$ and all $j=1, \ldots, J$.

Throughout the paper the focus is on pure-strategy equilibria. Before the full model including outside investors is analyzed, the simple case without new flow of funds is considered. 


\section{B. Equilibrium without Outside Investors}

In the absence of new fund flows, the fund managers' final assets under management can be determined after the realization of $\epsilon_{\alpha}$. The expected assets under management are as follows:

$$
\begin{aligned}
& \mathbb{E}\left[A_{j}(\text { Bench })\right]=a \\
& \mathbb{E}\left[A_{j}(\text { Option })\right]=a-p+\alpha
\end{aligned}
$$

The assumption $a \geq p$ is made to avoid default risk considerations, for cases where the fund manager is not able to pay premium $p$, which can induce risk-taking behavior derived from the fund managers' limited liability. Fund managers choosing Bench receive their initial assets under management $a$, while asset managers choosing Option expect to receive $a+N P V$ with $N P V:=\mathbb{E}\left[I_{\alpha}\right]=-p+\alpha$.

PROPOSITION 1: Without outside investors a Nash Equilibrium exists. In equilibrium all asset managers choose to invest in NPV-positive projects and refrain from investing in NPV-negative projects.

Proof. Choosing Option is uniquely optimal if $\mathbb{E}\left[A_{j}\left(\right.\right.$ Option, $\left.\left.x_{-j}\right)\right]>$ $\mathbb{E}\left[A_{j}\left(\right.\right.$ Bench, $\left.\left.x_{-j}\right)\right]$, which is the case for $p<\alpha$. Hence, the strategy profile $s^{*}=\left\{x_{j}^{*}=\right.$ Option for $\left.j=1, \ldots, J\right\}$ constitutes a Nash Equilibrium for $p<\alpha$. Similarly, choosing Bench is optimal if $\mathbb{E}\left[A_{j}(\right.$ Bench $\left.)\right]>$ $\mathbb{E}\left[A_{j}(\right.$ Option $\left.)\right]$, which is the case for $p>\alpha$. Accordingly, the strategy profile $s^{*}=\left\{x_{j}^{*}=\right.$ Bench for $\left.j=1, \ldots, J\right\}$ constitutes a Nash Equilibrium for $p>\alpha$. As $p<\alpha$ is equivalent to a positive $N P V_{p<\alpha}>0$ and $p<\alpha$ is equivalent to a negative $N P V_{p>\alpha}<0$, it can be concluded that all asset managers invest in positive NPV options and refrain from investing in negative NPV options in equilibrium.

In cases of NPV-neutral options, managers are indifferent between the different investment choices and every possible strategy profile constitut- 
ing a Nash Equilibrium. The Small Fund Industry model produces results consistent with classical financial theory. As long as no interaction with outside investors appears, risk-neutral managers take efficient investment decisions in the provided setting. The equilibria are efficient in an NPV sense, as all investors engage in positive NPV projects and refrain from negative NPV projects. The following section considers the full Small Fund Industry model, in which fund managers are able to attract external funds to increase growth of assets under management.

\section{Equilibria with Outside Investors}

After asset managers have chosen their investment strategy, end-investors observe the realization of $\epsilon_{\alpha}$. For $\epsilon_{\alpha}=1$, fund managers who chose the $O p$ tion strategy have $a-p+1$ assets under management, which is higher than the Bench managers' assets under management of $a$ for $p<1$. Hence, $\epsilon_{\alpha}=1$ leads to an equal distribution of $W$ among all Option managers, resulting in new flow of funds $\frac{W}{j_{o p t}^{*}}$, where $j_{\text {opt }}^{*}$ denotes the number of managers that chose the Option strategy. Similarly,for $\epsilon_{\alpha}=0$ and $p>0$, the fund managers following the Bench strategy realize higher returns and receive new funds of $\frac{W}{j_{b e n}^{*}}$, where $j_{\text {ben }}^{*}$ denotes the number of managers choosing the Bench strategy. Naturally $j_{\text {ben }}^{*}+j_{\text {opt }}^{*}=J$. Since $\mathbb{E}\left[\epsilon_{\alpha}\right]=\alpha$ this leads to the following reduced form expected final assets under management for $0<p<1:^{8}$

$$
\begin{aligned}
& \mathbb{E}\left[A_{j}(\text { Bench })\right]=a+(1-\alpha) \frac{W}{j_{\text {ben }}^{*}} \\
& \mathbb{E}\left[A_{j}(\text { Option })\right]=a-p+\alpha\left(1+\frac{W}{j_{\text {opt }}^{*}}\right)
\end{aligned}
$$

The expected final assets under management for each scenario allow us to solve for Nash-Equilibria in the reduced form simultaneous game.

\footnotetext{
${ }^{8}$ The cases of $p \leq 0$ and $p \geq 1$ are relegated to the Appendix (A), as it is straightforward to see that Bench is optimal given $p \geq 1$ and Option is optimal given $p \leq 0$.
} 
PROPOSITION 2: For $\alpha \leq \frac{1}{J}-\frac{N P V}{W}$, there exists a Nash Equilibrium with positive NPV investment opportunities in which all asset managers choose Bench.

Proof. It needs to be verified that for all asset managers switching from Bench in equilibrium Option is unprofitable. If all fund managers choose Bench then $j_{\text {ben }}^{*}=J$. All fund managers will show equal realized returns to end-investors, which leads to an equal distribution of $W$ among all $J$ funds. A deviation to Option leads to $j_{o p t}^{*}=1$. In case of a positive realization of $\epsilon_{\alpha}=1$, the deviating manager will receive all new flow of funds $W$. This leads to the necessary and sufficient condition for all $j$ managers to choose $x_{j}^{*}=$ Bench of

$$
\begin{aligned}
\mathbb{E}\left[A_{j}\left(\text { Bench }, x_{-j}^{*}=\{\text { Bench, }, \ldots, \text { Bench }\}\right)\right] & \geq \mathbb{E}\left[A_{j}\left(\text { Option }, x_{-j}^{*}=\{\text { Bench }, \ldots, \text { Bench }\}\right)\right] \\
a+\frac{W}{J} & \geq \underbrace{a-p}_{N P V}+\alpha(1+W) .
\end{aligned}
$$

Reformulating delivers the necessary and sufficient equilibrium condition $\alpha \leq \frac{1}{J}-\frac{N P V}{W}$ as stated in the proposition. Now the existence of positive NPV projects in equilibrium remains to be proved. The equilibrium condition can be restated as $N P V-\frac{W}{J}+\alpha W \leq 0$. For $\alpha$ sufficiently close to zero the left side becomes

$$
\lim _{\alpha \rightarrow 0}\left[N P V-\frac{W}{J}+\alpha W\right]=N P V-\frac{W}{J},
$$

and hence the condition is fulfilled for $0 \leq N P V \leq \frac{W}{J}$ with sufficiently small $\alpha>0$.

For a small enough payout likelihood $\alpha$ all fund managers are willing to forgo positive NPV projects. This misallocation is rooted in the incentive to attract new inflow of assets under management from outside investors who judge asset managers on past realized performance. The investment decisions in a framework with delegated portfolio management can be significantly driven by the payout frequency of an investment rather than by pure return arguments. The need to show positive returns distorts the in- 
vestment allocation decision away from the efficient NPV-based rational. Asset managers are unable to profit from investment opportunities which depend on rarely occurring events because in most cases these investments result in under-performance until the rare event happens. Moreover, from a capital market point of view, there can exist positive NPV investment projects that are unable to find money from fund managers. If the payout probability is too small, fund managers will decide not to invest, even if they are significantly overcompensated for the risk. The overall result is the inefficient allocation of investment capital for good investment opportunities with low a payout frequency.

PROPOSITION 3: For $\alpha \geq \frac{J-1}{J}-\frac{N P V}{W}$, there exists a Nash Equilibrium with negative NPV investment opportunities, in which all asset managers choose Option.

Proof. Similar to the previous case, for all asset managers choosing Option in equilibrium a profitable deviation to Bench must not be possible. All fund managers choosing Option leads to $j_{\text {ben }}^{*}=0$ and $j_{\text {opt }}^{*}=J$. All fund managers in the market have identical realized investment returns, which leads to a new inflow of funds of $\frac{W}{J}$ for each fund. A deviation to Bench results in $j_{\text {ben }}=1$. A negative realization of $\epsilon_{\alpha}=0$, results in the redirection of all new funds $W$ to the deviating fund manager. The necessary and sufficient condition for all $j$ managers to choose $x_{j}^{*}=$ Option is

$$
\begin{gathered}
\mathbb{E}\left[A_{j}\left(\text { Option }, x_{-j}=\{\text { Option }, \ldots, \text { Option }\}\right)\right] \\
\underbrace{a-p}_{N P V}+\alpha+\frac{W}{J} \geq a+(1-\alpha) W
\end{gathered}
$$

and reformulating delivers the necessary and sufficient equilibrium condition $\alpha \geq \frac{J-1}{J}-\frac{N P V}{W}$ as stated in the proposition. Now only the existence of negative NPV investment opportunities which fulfill the equilibrium condition, remains to be shown. The equilibrium condition can be restated as 
$N P V-W \frac{J-1}{J}+\alpha W \geq 0$. For a large enough $\alpha$ the left side becomes

$$
\lim _{\alpha \rightarrow 1}\left[N P V-W \frac{J-1}{J}+\alpha W\right]=N P V+\frac{W}{J} .
$$

Hence, the condition is always fulfilled for $-\frac{W}{J}<N P V<0$ for sufficiently large $\alpha<1$.

Asset managers are inclined to invest in bad projects if the probability of a positive payout is high enough, as a positive investment payout can attract external flow of funds. Hence, in expectation the manager is overcompensated for investing in a negative NPV project by the prospect of receiving new assets under management. This overinvestment stands in contrast to traditional financial theory and is rooted in the incentives induced by the flow of funds from external investors. The resulting equilibria are depicted in figure (1).

PROPOSITION 4: There exists a Nash Equilibrium for $\frac{1}{J}-\frac{N P V}{W}<\alpha<$ $\frac{J-1}{J}-\frac{N P V}{W}$ in which at least one fund manager chooses Bench and at least one fund manager chooses Option. Furthermore, if $\alpha$ is drawn from the continuous distribution over $(0,1)$ then $j_{\text {ben }}^{*}$ and $j_{\text {opt }}^{*}$ are unique with probability one.

Proof. One manager following the Option strategy, given all others follow the Bench strategy, requires $\alpha \geq \frac{1}{J}-\frac{N P V}{W}$ and one manager following the Bench when all others chose the Option strategy requires $\alpha \leq \frac{J-1}{J}-\frac{N P V}{W}$, as can be derived from condition (4) and (5). Moreover, in any equilibrium where a deviation from the equilibrium strategy leads to $j_{\text {ben }} \geq 1 \wedge j_{\text {opt }} \geq 1$, deviating from Option to Bench results in $j_{\text {ben }}=j_{\text {ben }}^{*}+1$ and hence requires

$$
\begin{aligned}
& \mathbb{E}\left[A_{j}\left(\text { Option }, x_{-j}^{*}\right)\right] \geq \mathbb{E}\left[A_{j}\left(\text { Bench }, x_{-j}^{*}\right)\right] \\
& a-p+\alpha\left(1+\frac{W}{j_{\text {opt }}^{*}}\right) \geq a+(1-\alpha) \frac{W}{j_{\text {ben }}^{*}+1} .
\end{aligned}
$$


Reformulating delivers $\underline{L}\left(j_{o p t}^{*}\right) \leq \alpha$ with $\underline{L}\left(j_{o p t}^{*}\right)=\frac{j_{o p t}^{*}}{J+1}-\frac{N P V}{W} \frac{\left(J-j_{o p t}^{*}+1\right) j_{o p t}^{*}}{J+1}$. Similarly, deviation from Bench to Option, increases number of Option managers to $j_{o p t}^{*}=j_{\text {opt }}^{*}+1$. This leads to the necessary equilibrium condition

$$
\begin{aligned}
\mathbb{E}\left[A_{j}\left(\text { Bench }, x_{-j}^{*}\right)\right] & \geq \mathbb{E}\left[A_{j}\left(\text { Option }, x_{-j}^{*}\right)\right] \\
a+(1-\alpha) \frac{W}{j_{\text {ben }}^{*}} & \geq a-p+\alpha\left(1+\frac{W}{j_{\text {opt }}^{*}+1}\right),
\end{aligned}
$$

which can be stated as $\alpha \leq \bar{L}\left(j_{o p t}^{*}\right)$ with $\bar{L}\left(j_{o p t}^{*}\right)=\frac{j_{o p t}^{*}+1}{J+1}-\frac{N P V}{W} \frac{\left(J-j_{o p t}^{*}\right)\left(j_{o p t}^{*}+1\right)}{J+1}$. It follows that for $\frac{1}{J}-\frac{N P V}{W}<\alpha<\bar{L}(1)$ exactly one manager chooses the Option strategy in equilibrium and for $\underline{L}(J-1)<\alpha<\frac{J-1}{J}-\frac{N P V}{W}$ exactly one manager follows the Bench strategy. Combining conditions (6) and (7) delivers the necessary equilibrium condition $\underline{L}\left(j_{\text {opt }}^{*}\right) \leq \alpha \leq \bar{L}\left(j_{\text {opt }}^{*}\right)$ for all equilibria with more than one manager following each strategy. As $\underline{L}\left(j_{\text {opt }}^{*}+1\right)=\bar{L}\left(j_{\text {opt }}^{*}\right)$ for every level of $\alpha \in(0,1)$ within $\frac{1}{J}-\frac{N P V}{W}<\alpha<$ $\frac{J-1}{J}-\frac{N P V}{W}$ an equilibrium can be determined with $j_{\text {ben }}^{*} \geq 1 \wedge j_{\text {opt }}^{*} \geq 1$ with some NPV. Asset managers are only indifferent between both strategies for $\alpha=\underline{L}\left(j_{\text {opt }}^{*}\right)$ or $\alpha=\bar{L}\left(j_{\text {opt }}^{*}\right)$. Due to $\frac{1}{J}-\frac{N P V}{W}<\bar{L}(1)<\bar{L}(2)<$ $\cdots<\bar{L}(J-2)<\frac{J-1}{J}-\frac{N P V}{W}$ the number of $j_{\text {ben }}^{*}$ and $j_{o p t}^{*}$ is otherwise uniquely determined. With $\alpha$ drawn from a continuous distribution over $(0,1)$ the probability for $\alpha=\underline{L}\left(j_{\text {opt }}^{*}\right) \vee \alpha=\bar{L}\left(j_{\text {opt }}^{*}\right)$ is zero. Hence, the number of asset managers following $j_{\text {ben }}^{*}$ and $j_{\text {opt }}^{*}$ in equilibrium is uniquely determined for every $\alpha$ drawn from the continuous distribution $(0,1)$ within $\frac{1}{J}-\frac{N P V}{W}<\alpha<\frac{J-1}{J}-\frac{N P V}{W}$.

In this third category of equilibria a segmented market arises from identical fund managers facing the same investment opportunity. A number of observations can be made. First, both positive and negative NPV investment opportunities can be supported in an equilibrium with managers following both strategies. Second, in each equilibrium with a non-zero NPV investment, misallocation of capital is induced. For the case of positive NPV options, some market participants do not invest and forgo the positive risk 
premium. Third, overinvestment in negative NPV options occurs as a positive number of funds managers decides to invest despite a negative NPV. In summary the equilibria can be grouped in three different categories:

(i) Homogeneous Bench equilibrium:

$$
j_{\text {ben }}^{*}=J, j_{\text {opt }}^{*}=0 \text { and } 0<\alpha \leq \frac{1}{J}-\frac{N P V}{W}
$$

(ii) Homogeneous Option equilibrium:

$$
j_{\text {ben }}^{*}=0, j_{\text {opt }}^{*}=1 \text { and } \frac{J-1}{J}-\frac{N P V}{W} \leq \alpha<1
$$

(iii) Heterogeneous Bench and Option equilibrium:

$$
j_{\text {ben }}^{*} \geq 1, j_{\text {opt }}^{*} \geq 1 \text { and } \frac{1}{J}-\frac{N P V}{W} \leq \alpha \leq \frac{J-1}{J}-\frac{N P V}{W}
$$

Figure (1) shows the homogeneous and heterogeneous equilibrium areas and regions of over- and underinvestment. The borders $\bar{L}\left(j_{\text {opt }}^{*}\right)$ and $\underline{L}\left(j_{\text {opt }}^{*}\right)$ between different heterogeneous equilibria are depicted as dotted lines for $J=5$.

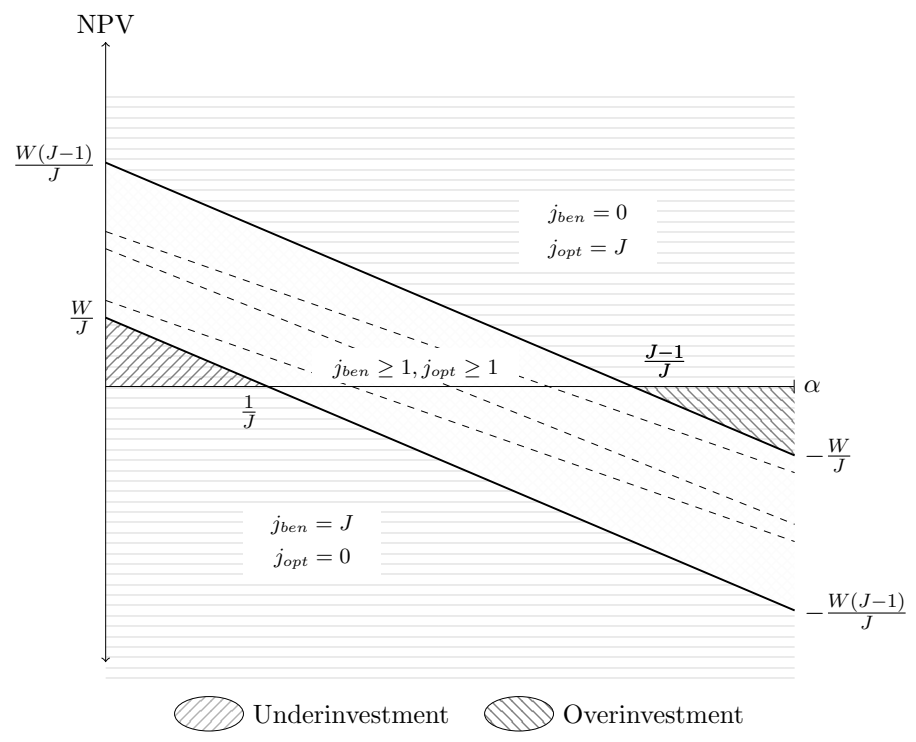

Figure 1. Homogeneous and heterogeneous equilibria 
Overall, the model offers an equilibrium explanation for over- and underinvestment in markets where portfolio decisions are delegated. Moreover, it provides a reason for heterogeneous investment behavior of investment funds without assuming heterogeneous beliefs or differing objective functions.

\section{Comparative Statics}

This section analyzes the effects of a change in the flow of funds $W$ and a change in total number of funds $J$. Moreover the special case for NPV-neutral investment opportunities is discussed.

\section{A. Change in Flow of Funds W}

For $W \mapsto 0$ all fund managers take the efficient NPV-based investment decision, as was shown in section (II.B). With $W \mapsto \infty$ the equilibrium conditions (8), (9), and (10) become independent of $N P V$. The number of investors who follow each strategy is entirely determined by $\alpha$. The result is depicted in figure (2).

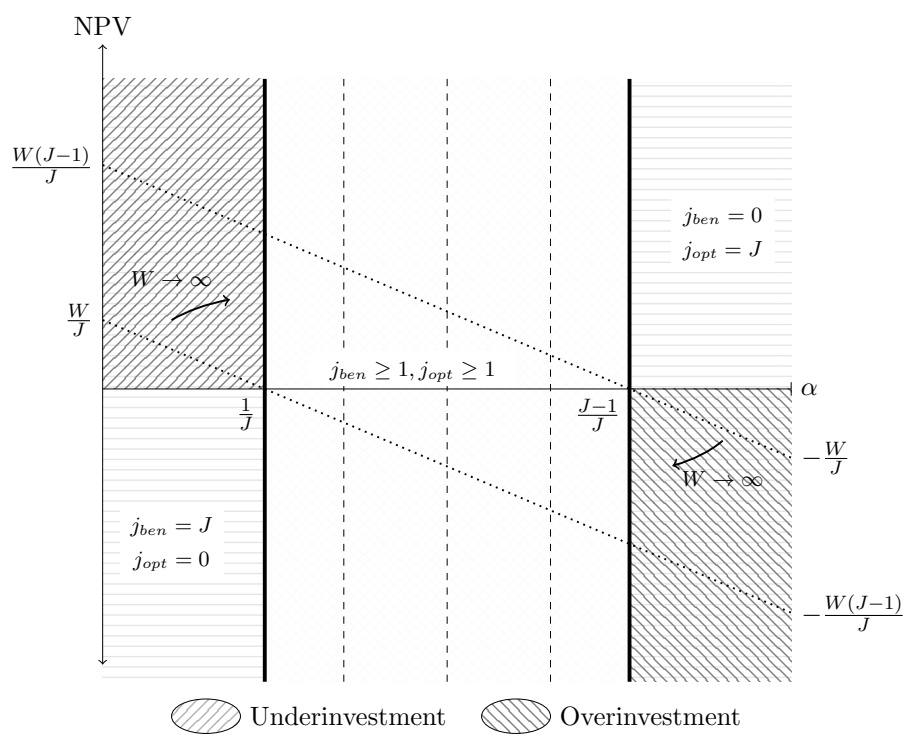

Figure 2. Equilibria with infinite flow of funds 
If the new flow of funds $W$ are large enough, they dominate the fund managers' investment decisions to a degree where NPV arguments become irrelevant. Payout frequency becomes the driving factor of asset allocation in the fund management market. Investments with a likely positive payout become advantageous and the possible negative return is not considered if the loss is seldom realized. Hence, fund managers are willing to take over-proportionally large risks if the negative outcome is unlikely enough. These results deliver a number of interesting implications. First, the lossgiven-default, ${ }^{9}$ or the absolute amount lost when the option does not deliver positive returns becomes nearly irrelevant in markets with delegated portfolio management with large amounts of new money inflows. Second, in the presence of significant new flow of funds the investment rationale of fund managers is no longer based on NPV considerations, but rather on the likelihood that investment opportunities will deliver some positive returns. Third, no fund manager will hedge against risks caused by crises, which occurs very rarely. This leads to large but infrequent cumulative losses for overall industry, resulting in a pattern of long steady growth and infrequent but heavy declines. Overall, a significant amount of new funds flowing into a market where portfolio decisions are delegated, marginalize NPV-based asset allocation decisions of fund managers and lead to investment with a likely positive payout irrespective of the assumed risks.

\section{B. Change in Fund Market Size J}

A decrease in the number of asset managers to $J=1$ eliminates the fund manager's incentive to attract new capital through his investment strategy. Accordingly, a single asset manager without competition takes an NPVbased decision in equilibrium. This is a straightforward but counterintuitive result: Lack of competition among fund managers leads to an efficient asset allocation in equilibrium. As competition increases to more than one fund manager and ultimately to an infinite number of asset managers $J \rightarrow \infty$,

\footnotetext{
${ }^{9}$ The loss-given-default in this papers context describes the overall loss for $\epsilon_{\alpha}=0$, which equals $-p$ and occurs with probability $1-\alpha$.
} 
homogeneous equilibria are replaced by heterogeneous equilibria. Revisiting condition (8) for an all Bench equilibrium, with $\lim _{J \rightarrow \infty} \frac{W}{J}-\alpha W=-\alpha W$ makes clear that underinvestment in positive NPV options in equilibria, where all fund managers follow the Benchmark, strategy is eliminated. Similarly, for condition (9) and $\lim _{J \rightarrow \infty} W \frac{J-1}{J}-\alpha W=W-\alpha W$ equilibria with all fund managers following the Option strategy can only exist for positive NPV options. The result is depicted in figure (3). Increased competition leads to a fragmented market in which misallocation of capital always occurs for non-zero NPV options. In equilibrium some asset managers always decide to invest, even in unprofitable options, and other managers never invest, even when offered profitable investments.

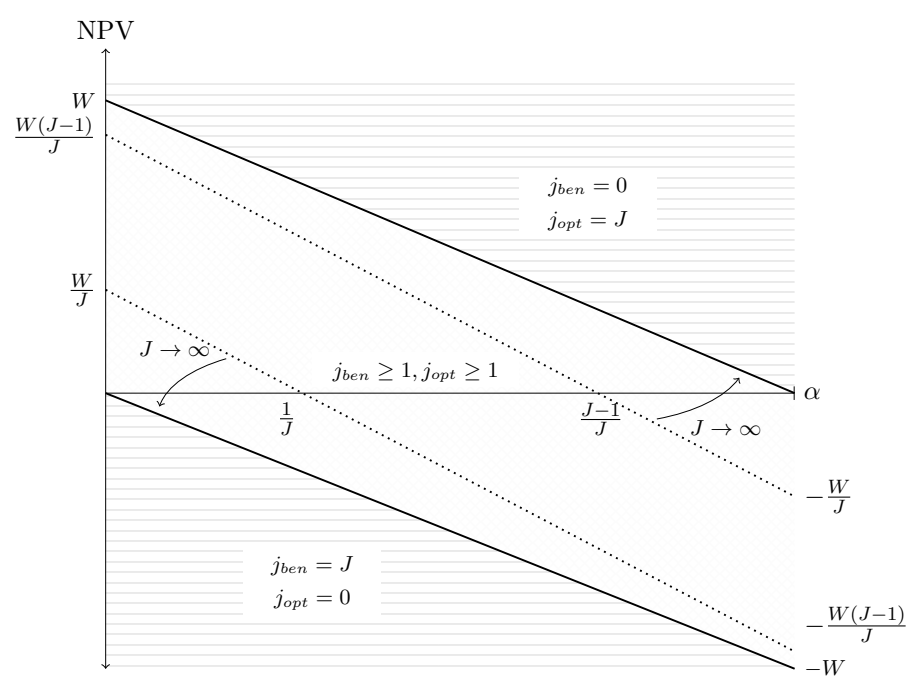

Figure 3. Equilibria with infinite large number of funds

\section{Special Case: Equilibria in Efficient Markets}

In this model the efficient market hypothesis (see Fama, 1970) translates into NPV-neutral options with $\alpha=p$. For $N P V=0$ condition (8) for an all Benchmark equilibrium simplifies to $\alpha \leq \frac{1}{J}$ and condition (9) for all Option equilibria simplifies to $\alpha \geq \frac{J-1}{J}$. For heterogeneous equilibria 
$\underline{L}\left(j_{\text {opt }}^{*}\right) \leq \alpha \leq \bar{L}\left(j_{\text {opt }}^{*}\right)$ can be rearranged to $\alpha(J+1)-1 \leq j_{\text {opt }}^{*} \leq \alpha(J+1)$.

A number of interesting observations can be made. Firstly, the number of asset managers following the Benchmark or Option strategy in each equilibrium does not depend on the amount of flow of funds $W$. As long as some new funds flow into the market, the market's asset allocation is uniquely driven by payout probability $\alpha$. Secondly, the amount of overall investment increases with $\alpha$, with all fund managers investing if $\alpha$ is high enough and no investment if $\alpha$ is low enough. This also means that the number of investing asset managers increases with the potential loss $p$, when no payout is delivered. Third, the potential of a large cumulated market loss rises with $\alpha$. NPV-neutral options with a high $\alpha$ imply a high premium payment $p$. Hence, in case of $\epsilon_{\alpha}=0$, which occurs with probability $1-\alpha$, all market participants suffer the loss $p$. The investment in high $\alpha$ options leads to a fund management market which can be interpreted as seemingly stable, frequently providing small but consistent payoffs - and which infrequently collapses and thereby causes over-proportionally large losses.

\section{Large Fund Industry Model}

In this model, prices for investment opportunities are determined by market supply and demand. Similar to the Small Fund Industry model, end-investors allocate their capital among those funds showing the highest realized performance. Fund managers maximize their assets under management, which depend on the performance of their investment and inflows from end-investors.

\section{A. Model Setup}

The economy is characterized by a continuum of asset managers $j \in[0,1]$ and a continuum of end-investors $i \in[0,1]$ with individual wealth $w$. Both groups are assumed to be equally distributed over the unit-interval with 
cumulative mass of one. ${ }^{10}$ Furthermore, there exists the investment opportunity $I_{\alpha}$ as defined in equation (1) in section (II.A). Asset managers can choose among three possible actions: To buy the investment opportunity (Long), to short-sell the investment opportunity (Short) or to not engage in any investment activity (Bench). All asset managers choosing $x_{j}=$ Long pay $p$ and receive one with probability $\alpha$. Accordingly, all asset managers with $x_{j}=$ Short receive $p$ and pay one with probability $\alpha$. All asset managers, including managers with $x_{j}=$ Bench maintain their assets under management $a$.

Since there is a continuum of fund managers, the influence on market prices of each individual manager is negligible. Each individual asset manager acts as price taker. Thus, for any given price $p \in \mathbb{R}$, each asset manager chooses an optimal investment decision out of $X=\{$ Long, Short, Bench $\}$. Put more rigorously, for any asset manager $j$ there exists a mapping $x_{j}$ : $\mathbb{R} \rightarrow X, p \mapsto x_{j}(p)$ such that $x_{j}(p)$ maximizes expected assets under management $\mathbb{E}\left[A_{j}\right]$ of the manager. Aggregating the investment decision across all asset managers determines the market supply $M S(p)$ and the market demand $M D(p)$ for any given price $p$ :

$$
\begin{aligned}
& \text { Market Supply: } M S(p)=\int_{0}^{1} \mathbf{I}_{\text {Short }}^{p}(j) d j \\
& \text { Market Demand: } M D(p)=\int_{0}^{1} \mathbf{I}_{\text {Long }}^{p}(j) d j
\end{aligned}
$$

where $\mathbf{I}_{\bar{x}}^{p}$ is defined by

$$
\mathbf{I}_{\bar{x}}^{p}(j)= \begin{cases}1 & \text { if } x_{j}(p)=\bar{x} \\ 0 & \text { else }\end{cases}
$$

\footnotetext{
${ }^{10}$ This assumption can be made without loss of generality as the asset manager's decision does not depend on the individual number of end-investors, but rather on the cumulative assets of all investors combined, which is scaled by wealth $w$.
} 
Market prices are determined by a Walrasian Auctioneer, matching market supply with market demand. The resulting Walrasian Equilibrium is subject to the further analysis.

DEFINITION 2 (Walrasian Equilibrium): A Walrasian Equilibrium is a pair of $\left(x_{j}^{*}(p) \forall j \in[0,1], p^{*}\right)$ such that:

(i) markets clear: $M S\left(p^{*}\right)=M D\left(p^{*}\right)$,

(ii) asset managers behave optimally given $\alpha$ and $p^{*}$ :

$\mathbb{E}\left[A_{j}\left(x_{j}^{*}(p)\right)\right] \geq \mathbb{E}\left[A_{j}\left(x_{j}(p)\right)\right], \forall x_{j} \in X$ and $j \in[0,1]$.

In the Walrasian Equilibrium markets clear and asset managers trade at the provided price. Situations where no price can be determined to result in any trading for a given $\alpha$, shall be labeled No Trade Equilibrium.

DEFINITION 3 (No Trade Equilibrium): $A$ No Trade Equilibrium is a pair of $\left(x_{j}^{*}(p) \forall j \in[0,1], \alpha\right)$ such that:

(i) For every possible $p$ either $M S\left(p^{*}\right)=0$ or $M D\left(p^{*}\right)=0$,

(ii) asset managers behave optimally given $\alpha$ and every possible $p$ : $\mathbb{E}\left[A_{j}\left(x_{j}^{*}(p)\right)\right] \geq \mathbb{E}\left[A_{j}\left(x_{j}(p)\right)\right], \forall x_{j} \in X$ and $j \in[0,1]$.

The timing is as follows: First, an investment opportunity for one fixed $\alpha \in(0,1)$ arises. Each asset manager chooses his investment decision which fixes market supply and demand. Second, the market clearing price $p^{*}$ is determined by a Walrasian Auctioneer. Third, the return from the investment is realized. Fourth, end-investors allocate their wealth $w$ among the asset managers with the highest observable assets under management. Fifth, the final assets under management, including new flow of funds, are determined. Before the full-fledged model is analyzed, the case with no outside investors is considered.

\section{B. Equilibrium without Outside Investors}

Without potential flow of outside funds from end-investors, final assets under management for each manager are solely determined by the investment decision $x \in X$ and price $p$. The final assets under management for each trading choice are as follows: 


$$
\begin{aligned}
& \mathbb{E}\left[A_{j}(\text { Bench })\right]=a \\
& \mathbb{E}\left[A_{j}(\text { Long })\right]=a-p^{*}+\alpha \\
& \mathbb{E}\left[A_{j}(\text { Short })\right]=a+p^{*}-\alpha
\end{aligned}
$$

This pins down the optimal investment strategy $x_{j}^{*}(p)$ for asset manager $j$ given price $p \in \mathbb{R}:{ }^{11}$

$$
x_{j}^{*}(p)= \begin{cases}\text { Short } & \text { for } p>\alpha, \\ \{\text { Long, Short, Bench }\} & \text { for } p=\alpha, \\ \text { Long } & \text { for } p<\alpha .\end{cases}
$$

PROPOSITION 5: In absence of new investor money, there exists a Walrasian Equilibrium. Moreover, all Walrasian Equilibria lead to NPV-neutral pricing with equilibrium price $p^{*}=\alpha$.

Proof. The Walrasian Equilibrium requires all asset managers to choose strategies which maximize expected assets under management and market clearing. Considering only optimal investment choices $x_{j}^{*}$ for all $j$ delivers the necessary first optimality condition. Second, market clearing $M S(p)=M D(p)$ requires the number of asset managers choosing Long to equal the number of asset managers choosing Short. The choice of different optimal strategies among asset managers given the same market price, is only possible for $p^{*}=\alpha$. Accordingly, an Walrasian Equilibrium can be constructed, in which an equal number of asset manager choose Long and Short respectively. Thus, the pair $\left(\left(x_{j}\left(p^{*}\right)=\operatorname{Long} \forall j \in(0,0.5], x_{j}\left(p^{*}\right)=\right.\right.$ Long $\left.\forall j \in(0.5,1]), p^{*}=\alpha\right)$ constitutes a Walrasian Equilibrium. Hence, a Walrasian Equilibrium exists.

\footnotetext{
${ }^{11}$ Under slight abuse of notation, let " $x_{j}(p)$ equal a set" mean that any element of the set is an optimal investment choice for manager $j$ given $p$.
} 
Any price $p^{*} \neq \alpha$ leads to $M S(p) \neq M D(p)$, as for $p^{*} \neq \alpha$ either only Long or Short is optimal for all asset managers. Hence, all Walrasian Equilibria require $p^{*}=\alpha$, which leads to an expected value for the investment opportunity of $\mathbb{E}\left[I_{\alpha}\right]=-p^{*}+\mathbb{E}\left[\epsilon_{\alpha}\right]=-\alpha+\alpha=0$, which is NPV-neutrality.

The market price of the investment opportunity leads to zero NPV, which is consistent with classical financial theory. Market participant are indifferent between buying, selling or refraining from trade at the equilibrium price. At the equilibrium price $p^{*}=\alpha$ a continuum of equilibria can be supported, which differ in trading amounts. As Bench is one optimal equilibrium response, each number of asset managers choosing Bench can be supported in a Walrasian Equilibrium, as long as the remaining asset managers choose Long and Short in equal amounts and $p^{*}=\alpha$. While the overall equilibrium market price is fixed, the amount of trading activity varies between different possible equilibria.

\section{Equilibrium with Outside Investors}

End-investors allocate their wealth $w$ to the fund with the highest realized return, after observing the realization of $\epsilon_{\alpha}$. Hence, at prices $p \leq 0$, Short is never the optimal response, as both other actions always deliver higher realized returns, with one of them attracting all new assets from endinvestors. Similarly, Long can never be a best response to price $p \geq 1$ as in this case the investment $I_{\alpha}$ can never deliver a positive payout for $\epsilon_{\alpha} \in\{0,1\}$ and consequently never attracts new flow of fund. Since there is no market supply for $p \leq 0$ and no market demand for $p \geq 1$ only prices $p^{*} \in(0,1)$ are feasible equilibrium prices. Only feasible prices are considered in the further analysis.

Market clearing demands $M S(p)=M D(p)$, hence the number of asset managers choosing Long equals the number of asset managers choosing Short for any market price $p^{*}$ determined by the Walrasian Auctioneer. In the presence of Long and Short managers, those following the Bench strategy will never be able to attract new flow of funds as they will always be 
outperformed by one other group. Hence, with an equal number of managers choosing Long and Short, the amount of fund flows received by each individual asset manager among the best performers is $2 w$.

For $\epsilon_{\alpha}=1$, each Long manager receives $2 w$, which happens with probability $\alpha$. With probability $(1-\alpha), \epsilon_{\alpha}$ equals zero, in which case every Short manager is among the best performers and receives $2 w$. This leads to the reduced form of final expected assets under management $\mathbb{E}\left[A_{j}\right]$ :

$$
\begin{aligned}
& \mathbb{E}\left[A_{j}(\text { Bench })\right]=a \\
& \mathbb{E}\left[A_{j}(\text { Long })\right]=a-p^{*}+\alpha(1+2 w) \\
& \mathbb{E}\left[A_{j}(\text { Short })\right]=a+p^{*}-\alpha(1+2 w)+2 w
\end{aligned}
$$

The optimal strategy needs to maximize final expected assets under management. Thus, Long is optimal if and only if both conditions $\mathbb{E}\left[A_{j}(\right.$ Long $\left.)\right] \geq$ $\mathbb{E}\left[A_{j}(\right.$ Short $\left.)\right]$ and $\mathbb{E}\left[A_{j}(\right.$ Long $\left.)\right] \geq \mathbb{E}\left[A_{j}\right.$ (Bench) $]$ hold simultaneously, which leads to $p \leq \alpha(1+2 w)-w$. Similarly, Short is optimal if and only if $\mathbb{E}\left[A_{j}(\right.$ Short $\left.)\right] \geq \mathbb{E}\left[A_{j}(\right.$ Long $\left.)\right]$ and $\mathbb{E}\left[A_{j}(\right.$ Short $\left.)\right] \geq \mathbb{E}\left[A_{j}(\right.$ Bench $\left.)\right]$, which is the case for $p \geq \alpha(1+2 w)-w$. Not investing by choosing Bench can never be a best response, as either Long or Short delivers higher expected assets under management for every possible $p^{*}$. This leads to the following optimal responses $x_{j}^{*}(p), \forall p \in(0,1)$ :

$$
x_{j}^{*}(p)= \begin{cases}\text { Short } & \text { for } p \geq \alpha(1+2 w)-w \\ \{\text { Long, Short }\} & \text { for } p=\alpha(1+2 w)-w \\ \text { Long } & \text { for } p \leq \alpha(1+2 w)-w\end{cases}
$$

Given the set of best responses for every feasible $p$ the equilibrium can be determined. 
PROPOSITION 6: In the presence of new investor money there exists a unique Walrasian Equilibrium for $p \in(0,1)$, with equilibrium price $p^{*}=$ $\alpha(1+2 w)-w$ and $M S\left(p^{*}\right)=M D\left(p^{*}\right)=\frac{1}{2}$.

Proof. The Walrasian Equilibrium requires optimal asset manager choices and market clearing. First, considering only optimal investment choices $x_{j}^{*}$ for all $j$ delivers the necessary optimality condition. Second, market clearing $M S(p)=M D(p)$ requires the number of asset managers choosing Long to equal the number of asset managers choosing Short. This requires both Long and Short to be a best answer to $p^{*}$, which is possible for $p^{*}=\alpha(1+2 w)-$ $w$. Both trading actions $x_{j} \in\{$ Long, Short $\}$ are utility maximizing at the equilibrium price. Hence, the pair $\left[\left(x_{j}\left(p^{*}\right)=\right.\right.$ Short $\forall j \in(0,0.5], x_{j}\left(p^{*}\right)=$ Long $\left.\forall j \in(0.5,1]), p^{*}=\alpha(1+2 w)-w\right]$ constitutes a Walrasian Equilibrium. Thus, a Walrasian Equilibrium exists.

Any other price $p^{*} \neq \alpha(1+2 w)-w$ leads to $M S(p) \neq M D(p)$. Consequently, the only possible Walrasian Equilibrium price is $p^{*}=\alpha(1+2 w)-w$. In order to support $p^{*}=\alpha(1+2 w)-w$ half the number of asset managers need to choose Long and the other half Short, which leads to $M S(p)=$ $M D(p)=\frac{1}{2}$. Hence, the Walrasian Equilibrium is unique as any other price $p \neq \alpha(1+2 w)-w$, would not lead to market clearing.

The market equilibrium prices $p^{*}=\alpha(1+2 w)-w$ can be restated as $p^{*}=\alpha+2 w\left(\alpha-\frac{1}{2}\right)$, which shows that new flow of funds from outside distorts the market prices by $2 w\left(\alpha-\frac{1}{2}\right)$ compared with the case of no outside capital. The price for investments with payout probabilities lower that one-half are undervalued compared to the NPV-neutral price while investments with payout frequencies higher than one-half are overvalued in equilibrium. The incentive to receive new assets under management marginalizes the effect of the NPV and leads to an over-proportionally high demand for options with frequent positive payoffs and an over-proportionally high supply for options with infrequent positive payoffs. Overall, only investment opportunities with $\alpha=\frac{1}{2}$ are priced efficiently in an NPV sense. 
PROPOSITION 7: $A$ No Trade Equilibrium exists for all $\alpha \leq \frac{w}{1+2 w}$ and all $\frac{1+w}{1+2 w} \leq \alpha$.

Proof. For $\alpha \leq \frac{w}{1+2 w}$ and $p \leq 0$, Long is the unique best response, which leads to $M S(p \leq 0)_{\alpha \leq \frac{w}{1+2 w}}=0$ following from proposition (9) in the appendix. Following from equation (15), for $\alpha \leq \frac{w}{1+2 w}$ and $p>0$, Short is the unique best response, leading to $M D(p>0)_{\alpha \leq \frac{w}{1+2 w}}=0$. Hence, for $\alpha \leq \frac{w}{1+2 w}$ and all possible $p$ either $M S$ or $M D$ is zero, given the optimal behavior of all market participants. Following the same logic as in proposition (8) in the appendix, for $\frac{1+w}{1+2 w} \leq \alpha$ and $p \geq 1$, the unique best response is Short resulting in $M D(p \geq 1)_{\frac{1+w}{1+2 w} \leq \alpha}=0$. For $\frac{1+w}{1+2 w} \leq \alpha$ and $p<1$ the unique best response is Long, which again follows from equation (15), and provides $M S(p<1) \frac{1+w}{1+2 w} \leq \alpha=0$. For $\frac{1+w}{1+2 w} \leq \alpha$ all possible prices $p$ lead to $M S=0$ or $M D=0$. Hence, if all market participants behave optimally, a No Trade Equilibrium exists for all $\alpha \leq \frac{w}{1+2 w}$ and $\frac{1+w}{1+2 w} \leq \alpha$.

Only prices $0<p<1$ lead to market clearing. The consequence is market failure for investment opportunities with $\alpha \leq \frac{w}{1+2 w}$ and $\frac{1+w}{1+2 w} \leq \alpha$.

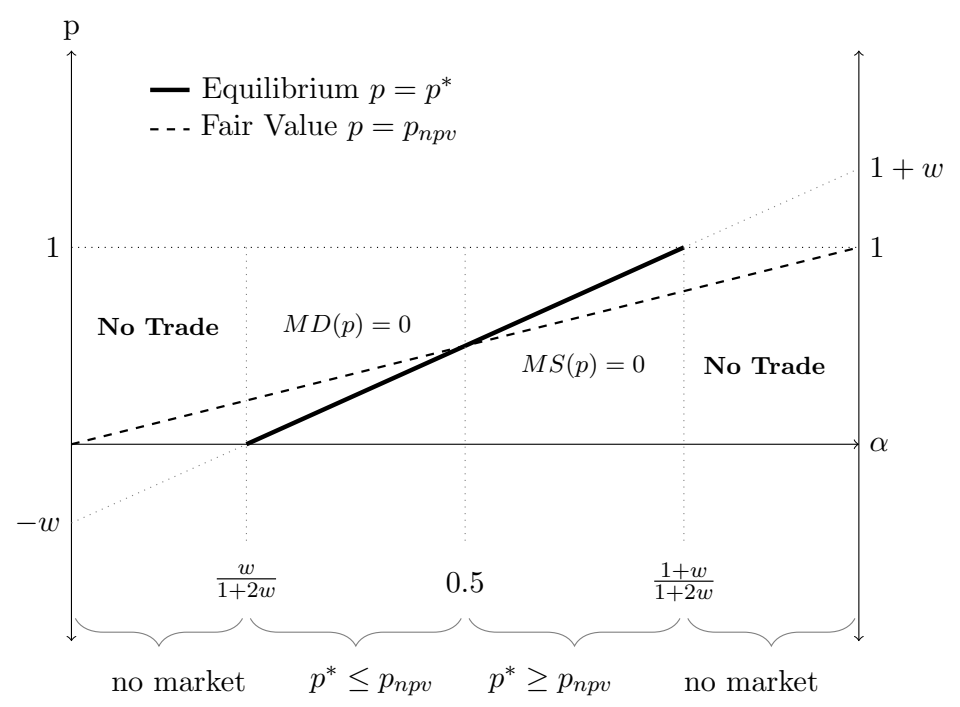

Figure 4. Market prices in equilibrium 
Thus, the presence of new flow of funds leads not only to mispricing of investment opportunities but to complete market failure for options with sufficiently low or sufficiently high payout probabilities. The final equilibrium is depicted in figure (4). The price $p_{n p v}$ depicts the premium $p=\alpha$ leading to a zero NPV option.

The effect of new funds being distributed to asset managers as a function of past performance can distort the market price of risk away from their fair value. A number of interesting observations can be made. The first result is that only investment opportunities with a payout probability of one-half are fairly priced in equilibrium and generate an NPV of zero for asset managers. The second result is that investment opportunities with a payout frequency lower than one-half are undervalued. The undervaluation increases with decreasing $\alpha$ and reaches its maximum at the lowest level of $\alpha$ for which options are traded in the market. Third, investment options with payout frequencies higher than one-half are overvalued in equilibrium, which allows negative NPV projects to be traded in equilibrium. The overvaluation increases with the probability $\alpha$ that the option will generate positive cash flow. The overvaluation reaches its maximum at the highest level of $\alpha$ for which trading occurs. The fourth result is market failure for options with sufficiently high and sufficiently low payout probabilities. No asset manager is willing to engage in an investment which pays off too rarely or to short-sell an investment which pays out too often, as both strategies are unlikely to secure new investments from end-investors.

\section{Comparative Statics}

The following section analyzes the effects of a change in flow of funds $w$. A decrease of $w \mapsto 0$ leads to the special case without external investors discussed in section (IV.B), in which the asset allocation is efficient. An increase of $w \mapsto \infty$ for $p^{*}=\alpha(1+2 w)-w$ leads to: 


$$
\lim _{w \rightarrow \infty} p^{*}(w, \alpha)= \begin{cases}-\infty, & \text { for } \alpha<\frac{1}{2} \\ \frac{1}{2}, & \text { for } \alpha=\frac{1}{2} \\ \infty, & \text { for } \alpha>\frac{1}{2}\end{cases}
$$

Trade only occurs for investment opportunities with payout probability of one-half. An increase in flow of funds narrows the range of traded investment options to options without extreme payout frequencies. The result is counterintuitive, as a higher availability of assets available for investments leads to a decrease in the range of investment opportunities traded in the market.

\section{E. Effect on Market Implied Probabilities}

Without new flow of funds, the equilibrium price $p^{*}$ equals the real implied payout probability $\alpha$. The inflow of new funds leads to a distortion of equilibrium prices. Assuming a naive observer were to neglect the new flow of funds effect in an attempt to calculate the implied payout probability $\alpha_{i m p l}$ from observed traded market prices $p^{*}=\alpha(1+2 w)-w$, he would be subject to the following bias:

$$
\alpha_{i m p l}-\alpha=2 w\left(\alpha-\frac{1}{2}\right), \text { for } \frac{w}{1+2 w} \leq \alpha \leq \frac{1+w}{1+2 w}
$$

Options with implied probabilities of close to zero still have a real payout probability of $\frac{w}{1+2 w}$ and options with a payout probability of less than $\frac{w}{1+2 w}$ are not traded. Similarly, seemingly certain investment opportunities with implied probabilities marginally close to one, only have a real payout probability of $\frac{1+w}{1+2 w}$ and options a with higher real payout probability are not traded. Overall, extreme implied probabilities close to zero and one are misjudged by a naive market, which does not account for new flow of funds when observing market prices. This can lead to an observable bias between naively calculated implied probabilities and empirical frequencies of financial market data. Implied probabilities for likely events are overestimated, while implied probabilities of rare events are underestimated in this setting. 
Moreover, the difference between the implied and the real payout probability $\alpha_{i m p l}-\alpha$ increases with increasing $w$ for all traded options with $\alpha \neq \frac{1}{2}$. In the most extreme case with $w$ growing close to infinity, the real payout probability of an option with $\alpha_{i m p l}$ of almost zero is close to one-half. Vice versa the event assumed to be safe with $\alpha_{i m p l}$ close to one only occur with $\alpha=\frac{1}{2}$.

Overall, an increase in new funds leads to a decrease in trading for $\alpha$ unequal to one-half, increasing mispricing of risk and distortions in implied probabilities. Seemingly unlikely events happen more often than implied probabilities suggest and seemingly secure investments fail more often than expected by naive market observers.

\section{Conclusion}

For a vast amount of assets, the investment decision is delegated to asset managers. Previous literature is mainly focused on the relation between asset owner and asset manager. This paper takes the empirical convex relation between fund performance and flow of funds as given and analyzes the effects on asset allocation and pricing of investment opportunities in competitive markets. The Small Fund Industry model considers a financial market where the fund industry takes exogenous prices as given, resulting in equilibria with inefficient investment behavior. First, all asset managers invest in negative NPV options with high payout probability. Second, all asset managers refrain from investing in positive NPV opportunities with low payout probability. Third, investments with payout probabilities which are neither extremely high nor extremely low result in a fragmented market in which some asset managers decide to invest while others do not. For sufficiently large new fund flows, efficient NPV-based decisions are marginalized and only payout probabilities are considered. The model suggests investment behavior leading to a pattern of steady rise interrupted by infrequent large losses in the mutual fund industry.

The Large Fund Industry model considers a competitive financial market in which prices are determined endogenously. As a result, first, investment 
opportunities with a payout probability below one-half are undervalued, leading to positive risk premia. Second, investment opportunities with a payout probability above one-half are overvalued, resulting in negative risk premia. Only investment options with a payout probability of exactly onehalf are valued at their expected value in equilibrium. The third result is complete market failure and absence of trading for investments with both sufficiently high or sufficiently low payout frequencies. The market failure widens for increasing amounts of new flow of funds, with the limit case where only options with payout probability of one-half can be traded. Moreover the paper delivers two important implications. First, when implied payout probabilities are calculated from market prices without considering the flow-of-funds effect, wrong conclusions about the real payout probability are derived. Market implied probabilities underestimate the real probability of rare payouts and overestimate the real probability of likely payouts. Second, identical asset managers follow different investment strategies and engage in trading with each other in equilibrium. Hence, convex flow of funds from end-investors give rise to trading activity between identical investors at market equilibrium prices.

In summary, this paper answers the question of how competitive financial market prices and asset allocations decisions are affected by fund flows from end-investors to asset managers. It provides reasons for misallocation of capital, mispricing of investment opportunities, and the resulting distortions in option implied probabilities. Furthermore, it delivers an equilibrium explanation for trading activity and reasoning for heterogeneous investment behavior among identical fund managers. 


\section{Appendix A. Feasible Equilibrium Prices}

PROPOSITION 8: Bench is always the optimal choice for $p \geq 1$

Proof. For $p=1$ and $\epsilon_{\alpha}=1$ the realized returns from both strategies are equal and lead to a distribution of the new flow of funds among all asset $J$ managers. Accordingly, the expected final assets under management for $p=1$ are:

$$
\begin{aligned}
& \mathbb{E}\left[A_{j}(\text { Bench })\right]=a+\alpha \frac{W}{J}+(1-\alpha) \frac{W}{j_{\text {ben }}} \\
& \mathbb{E}\left[A_{j}(\text { Option })\right]=a-p+\alpha\left(1+\frac{W}{J}\right)
\end{aligned}
$$

The condition for $\mathbb{E}\left[A_{j}(\right.$ Bench $\left.)\right]>\mathbb{E}\left[A_{j}(\right.$ Option $\left.)\right]$ is:

$$
\begin{gathered}
a+\alpha \frac{W}{J}+(1-\alpha) \frac{W}{j_{\text {ben }}}>a-p+\alpha\left(1+\frac{W}{J}\right) \\
(1-\alpha) \frac{W}{j_{\text {ben }}}>-p+\alpha
\end{gathered}
$$

Which is always fulfilled for $p=1$, since $\alpha<1$ by definition. Hence, the Bench is always optimal for $p=1$. For $p>1$ the realized returns from Bench are always higher, since $\mathbb{I}_{\alpha}=-p+\epsilon_{\alpha}<0$, for $p>1$ and for all $\epsilon_{\alpha} \in\{0,1\}$. So Bench delivers higher realized returns and receives all (positive) new flow of funds in each possible scenario for $p>1$. Accordingly, Bench is always optimal for $p \geq 1$.

PROPOSITION 9: Option is always the optimal choice for $p \leq 0$

Proof. For $p=0$ and $\epsilon_{\alpha}=0$, leads to new fund inflow $\frac{W}{J}$ from end-investors to all asset managers. Thus, expected final assets under management for $p=0$ are: 


$$
\begin{aligned}
& \mathbb{E}\left[A_{j}(\text { Bench })\right]=a+(1-\alpha) \frac{W}{J} \\
& \mathbb{E}\left[A_{j}(\text { Option })\right]=a+\alpha\left(1+\frac{W}{j_{\text {opt }}^{*}}\right)+(1-\alpha) \frac{W}{J}
\end{aligned}
$$

The condition for $\mathbb{E}\left[A_{j}(\right.$ Option $\left.)\right]>\mathbb{E}\left[A_{j}(\right.$ Bench $\left.)\right]$ is:

$$
\begin{gathered}
a+\alpha\left(1+\frac{W}{j_{o p t}^{*}}\right)+(1-\alpha) \frac{W}{J}>a+(1-\alpha) \frac{W}{J} \\
\alpha\left(1+\frac{W}{j_{o p t}^{*}}\right)>0
\end{gathered}
$$

Which is always fulfilled as $\alpha>0$ by definition. Thus, Option is always optimal for $p=0$. Moreover $p<0$ leads to higher realized returns for $O p$ tion, since $\mathbb{I}_{\alpha}=-p+\epsilon_{\alpha}>0$, for $p<0$ and for all $\epsilon_{\alpha} \in\{0,1\}$. Therefor, Option delivers higher realized returns and additionally attracts all new flow of funds for $p<0$. Hence, Option is always optimal for $p \leq 0$. 


\section{REFERENCES}

Admati, Anat R., and Paul Pfleiderer, 1997, Does it all add up? Benchmarks and the compensation of active portfolio managers, Journal of Business $70,323-350$.

Agarwal, Vikas, Naveen D. Daniel, and Narayan Y. Naik, 2004, Flows, performance, and managerial incentives in hedge funds, Working paper, London Business School.

Baquero, Guillermo, and Marno Verbeek, 2005, A portrait of hedge fund investors: Flows, performance and smart money, Working paper, RSM Erasmus University.

Baquero, Guillermo, and Marno Verbeek, 2006, Do sophisticated investors believe in the law of small numbers?, Working paper, RSM Erasmus University.

Basak, Suleyman, and Dmitry Makarov, 2014, Strategic asset allocation in money management, Journal of Finance 69, 179-217.

Basak, Suleyman, and Anna Pavlova, 2013, Asset prices and institutional investors, American Economic Review 103, 1728-1758.

Basak, Suleyman, Anna Pavlova, and Alexander Shapiro, 2007, Optimal asset allocation and risk shifting in money management, Review of Financial Studies 20, 1583-1621.

Basak, Suleyman, Alex Shapiro, and Lucie Teplá, 2006, Risk management with benchmarking, Management Science 52, 542-557. 
Berk, Jonathan B., and Richard C. Green, 2004, Mutual fund flows and performance in rational markets, Journal of Political Economy 112, 12691295 .

Binsbergen, Jules H. van, Michael W. Brandt, and Ralph S. Koijen, 2008, Optimal decentralized investment management, Journal of Finance 63, 1849-1895.

Brennan, Michael J., and Feifei Li, 2008, Agency and asset pricing, Working paper, University of California, Los Angeles (UCLA).

Brown, Keith C., W. Van Harlow, and Laura T. Starks, 1996, Of tournaments and temptations: An analysis of managerial incentives in the mutual fund industry, Journal of Finance 51, 85-110.

Chevalier, Judith, and Glenn Ellison, 1999, Career concerns of mutual fund managers, Quarterly Journal of Economics 114, 389-432.

Chiang, Kevin C., 1999, Survival, tournament, and asset allocation strategy in the mutual fund industry, Working paper, Louisiana State University.

Cornell, Bradford, and Richard Roll, 2005, A delegated-agent asset-pricing model, Financial Analysts Journal 61, 57-69.

Cuoco, Domenico, and Ron Kaniel, 2011, Equilibrium prices in the presence of delegated portfolio management, Journal of Financial Economics 101, $264-296$.

Dasgupta, Amil, and Andrea Prat, 2006, Financial equilibrium with career concerns, Theoretical Economics 1, 67-93. 
DeMarzo, Peter, Ron Kaniel, and Ilan Kremer, 2007, Technological innovation and real investment booms and busts, Journal of Financial Economics $85,735-754$.

Ding, Bill, Mila Getmansky, Bing Liang, and Russ Wermers, 2009, Share restrictions and investor flows in the hedge fund industry, Working paper, University of Massachusetts.

Fama, Eugene F., 1970, Efficient capital markets: A review of theory and empirical work, Journal of Finance 25, 383-417.

Frank, Robert H., 1985, Choosing the right pond: Human behavior and the quest for status. (Oxford University Press, Oxford).

Gennaioli, Nicola, Andrei Shleifer, and Robert Vishny, 2015, Money doctors, The Journal of Finance 70, 91-114.

Goriaev, Alexei, Frederic Palomino, and Andrea Prat, 2003, Mutual fund tournament: Risk taking incentives induced by ranking objectives, Working paper, London School of Economics.

Gruber, Martin J., 1996, Another puzzle: The growth in actively managed mutual funds, Journal of Finance 51, 783-810.

Guercio, Diane Del, and Jonathan Reuter, 2014, Mutual fund performance and the incentive to generate alpha, Journal of Finance 69, 1673-1704.

Gyongyi, Loranth, and Sciubba Emanuela, 2006, Relative performance, risk and entry in the mutual fund industry, Topics in Economic Analysis $\&$ Policy 6, 1-28. 
Investment Company Institute, 2015, 2015 Investment Company Fact Book (Investment Company Institute, Washington DC).

Ippolito, Richard A., 1992, Consumer reaction to measures of poor quality: Evidence from the mutual fund industry, Journal of Law and Economics $35,45-70$.

Jans, Rob, and Róger Otten, 2008, Tournaments in the UK mutual fund industry, Managerial finance 34, 786-798.

Kahneman, Daniel, and Amos Tversky, 1972, Subjective probability: A judgment of representativeness, Cognitive Psychology 3, 430-454.

Kapur, Sandeep, and Allan Timmermann, 2005, Relative performance evaluation contracts and asset market equilibrium, The Economic Journal 115, 1077-1102.

Kempf, Alexander, and Stefan Ruenzi, 2008, Tournaments in mutual-fund families, Review of financial studies 21, 1013-1036.

Khorana, Ajay, 1996, Top management turnover an empirical investigation of mutual fund managers, Journal of Financial Economics 40, 403-427.

Lakonishok, Josef, Andrei Shleifer, Robert W. Vishny, Oliver Hart, and George L. Perry, 1992, The structure and performance of the money management industry, Brookings Papers on Economic Activity. Microeconomics 1992, 339-391.

Li, Wei, and Ashish Tiwari, 2006, On the consequences of mutual fund tournaments, Working paper, University of Iowa. 
Lynch, Anthony W., and David K. Musto, 2003, How investors interpret past fund returns, Journal of Finance 58, 2033-2058.

Nagarajan, Nandu J., K. Sivaramakrishnan, and Sri S. Sridhar, 1995, Managerial entrenchment, reputation and corporate investment myopia, Journal of Accounting, Auditing and Finance 10, 565-585.

Osborne, Martin J., and Ariel Rubinstein, 1998, Games with procedurally rational players, American Economic Review 88, 834-847.

Patel, Jayendu, Richard Zeckhauser, and Darryll Hendricks, 1991, The rationality struggle: Illustrations from financial markets, American Economic Review 81, 232-236.

Patel, Jayendu, Richard Zeckhauser, and Darryll Hendricks, 1994, Investment flows and performance: Evidence from mutual funds, cross-border investments and new issues, Japan, Europe, and international financial markets: Analytical and empirical perspectives 51-72.

Rabin, Matthew, 2002, Inference by believers in the law of small numbers, Quarterly Journal of Economics 117, 775-816.

Rabin, Matthew, and Dimitri Vayanos, 2010, The gambler's and hot-hand fallacies: Theory and applications, Review of Economic Studies 77, 730778.

Reed, Adam V., and Ling Wu, 2005, Racing the clock: Benchmarking or tournaments in mutual fund risk-shifting?, Working paper, University of North Carolina. 
Rennie, Edward P., and Thomas J. Cowhey, 1990, The successful use of benchmark portfolios: A case study, Financial Analysts Journal 46, 1826.

Sharpe, William F., 1981, Decentralized investment management, Journal of Finance 36, 217-234.

Sirri, Erik R., and Peter Tufano, 1998, Costly search and mutual fund flows, Journal of Finance 53, 1589-1622.

Smith, Keith V., 1978, Is fund growth related to fund performance?, The Journal of Portfolio Management 4, 49-54.

Spiegler, Ran, 2006, The market for quacks, Review of Economic Studies $73,1113-1131$.

Spitz, Edward A., 1970, Mutual fund performance and cash inflows, Applied Economics 2, 141-145.

Thakor, Anjan, 1990, Investment myopia and the internal organization of capital allocation decisions, Journal of Law, Economics, \& Organization $6,129-154$.

Tversky, Amos, and Daniel Kahneman, 1971, Belief in the law of small numbers, Psychological bulletin 76, 105-110.

Zheng, Lu, 1999, Is money smart? A study of mutual fund investors' fund selection ability, Journal of Finance 54, 901-933. 


\section{Recent ESMT Working Paper}

ESMT No.

LeChatelier-Samuelson principle in games and pass-through of shocks

Alexei Alexandrov, Consumer Financial Protection Bureau

Özlem Bedre-Defolie, ESMT European School of Management and Technology

Contracts as a barrier to entry when buyers are non-pivotal

Özlem Bedre-Defolie, ESMT European School of Management and Technology

Gary Biglaiser, University of North Carolina, Chapel Hill

What do patent-based measures tell us about product commercialization? Evidence from the pharmaceutical industry

Stefan Wagner, ESMT European School of Management and Technology

Simon Wakeman, New Zealand Productivity Commission

Hedge fund flows and performance streaks: How investors weigh information

Guillermo Baquero, ESMT European School of Management and Technology

Marno Verbeek, Rotterdam School of Management, Erasmus University

A price concentration study on European mobile telecom markets: Limitations and insights

Pauline Affeldt, E.CA Economics, ESMT European School of Management and Technology Rainer Nitsche, E.CA Economics

Two birds, one stone? Positive mood makes products seem less useful for multiplegoal pursuit

Anastasiya Pocheptsova, R. H. Smith School of Business, University of Maryland Francine Espinoza Petersen, ESMT European School of Management and Technology

Jordan Etkin, Fuqua School of Business, Duke University

Contracting in medical equipment maintenance services: An empirical investigation

Tian Chan, INSEAD

Francis de Véricourt, ESMT European School of Management and Technology

Omar Besbes, Columbia University 